\title{
TRABALHO ÔNTICO-CONCRETO E A SUPERAÇÃO DIALÉTICA DO SER SOCIAL
}

\section{ONTOLOGICAL CONCRETE WORK AND THE DIALECTICAL OVERCOMING OF SOCIAL BEING}

\author{
Vicente Juciê Sobreira Junior ${ }^{1}$ \\ Maria José Pires Cardozo ${ }^{2}$
}

\section{RESUMO}

O artigo propõe abordar o fragmento do estudo desenvolvido no Programa de Pós-Graduação em Educação, na Universidade Federal do Maranhão, tratando o trabalho enquanto categoria ontológica central na constituição do ser social. Parte-se da concepção marxiana aprofundada por Lukács na Ontologia do Ser Social, oferecendo indicativos onto-metodológicos e materialistas às complexificações contínuas e dialéticas das relações sociais em cada momento de superação. Assim, intenta-se ampliar o diálogo acerca da totalidade na práxis humana como ponto de partida necessário à compreensão das determinações constitutivas da realidade concreta fragmentária dos sujeitos, em busca de processos emancipatórios viabilizantes que se autoinvalidam na lógica antitética do capital.

PALAVRAS-CHAVE: Trabalho- Ser social- Dialética.

\begin{abstract}
This article proposes to approach the fragment of the study developed on Education Graduation Program at the Universidade Federal do Maranhão, dealing with work as a central ontological category in the constitution of human being. We depart from the enhanced Marxian concept by Lukács on Social Human Ontology, offering onto-methodological and materialistic indicatives to the ongoing and dialectical complexity of social relations in each moment of overcoming. Thus, we try to amplify the dialogue on human praxis totality as a necessary starting point to understand the constituted determinations of concrete fragmented reality of subjects, seeking for emancipating processes that nullify themselves on the unethical capital logic.
\end{abstract}

KEYWORDS: Work- Social being- Dialects. 


\section{INTRODUÇÃO}

O trabalho proposto trata-se de um fragmento da pesquisa realizada no Programa de Pós-Graduação em Educação, na Universidade Federal do Maranhão, abordando o trabalho como categoria de centralidade ontológica sob um lócus marxiano-lukacsiano, compreendendo-o enquanto atividade imprescindível à existência humana, em sua centralidade ontológica fundante do ser social (LUKÁCS, 2013).

Intenta-se, fundamentalmente, captar seu metabolismo, desmistificando as manifestações na "pseudoconcreticidade", como condição do aparente, apropriando-se dos sentidos da realidade concreta, exigente de se fazer conhecidas as formas assumidas pela "práxis fragmentária" na lógica do capital e sua incidência sobre a atividade humana (KOSIK, 1976). Com isso, entender os nexos complexos nessa totalidade concreta é questão necessária à ampliação do campo teórico do debate acerca da relação entre capital e trabalho, compreendendo esse contexto de mediação antitética como ponto decisivo às demais determinações constitutivas do ser.

Assim, exige-se um olhar dialético sobre a realidade. Porém, tem-se consciência que desenvolver qualquer esboço teórico-metodológico nessa perspectiva torna-se uma construção hercúlea, tendo em vista as nuances variadas sobre a temática do trabalho na lógica do capital, em que se constroem inúmeras tentativas explicativas acerca dos problemas que circundam o debate. Por isso, necessita-se apreendê-lo de forma precisa, tornando-se imprescindível sua fundamentação como contraponto ao sentido de naturalização posto sobre a sombra do aparente-hegemônico neoliberal. Contudo, ao estabelecer qualquer "ofensiva", impõe-se a exigência de um (re) pensar de forma lúcida acerca da crise do capital no contexto atual, e essa ação (re) volta-se à exigência de (re) fundamentos acerca das categorias construídas a partir da realidade existente, do concreto.

\section{TRABALHO E FUNDAÇÃO DO SER SOCIAL}

O trabalho enquanto categoria de centralidade ontológica na constituição do ser em sua forma integral surge como uma determinação real do homem, pensado como representação cotidiana plena, como resultado de uma totalidade concreta correspondente a 
uma forma de sociedade, como mediação entre homem e natureza que passa a ocupar posição de centralidade na relação entre "consciência e ambiente" (RANIERE, 2011), em um processo em que os homens organizam o seu metabolismo com o meio natural, na relação de duplo movimento, considerando que quando o homem transforma a natureza, modifica também a si mesmo (MARX, 2013).

De acordo com Marx (2013, p. 211), o ser humano por meio do trabalho

[...] põe em movimento as forças naturais de seu corpo - braços, pernas, cabeça e mãos -, a fim de apropriar-se dos recursos da natureza, imprimindo-lhes forma útil à vida humana. Atuando assim sobre a natureza externa e modificando-a, ao mesmo tempo modifica a sua própria natureza. Desenvolve potencialidades nela adormecidas e submete ao seu domínio o jogo das forças naturais.

Nessa ótica, Marx considera o trabalho imerso em um "processo que participam o homem e a natureza (...) em que o ser humano, com sua própria ação, impulsiona, regula e controla seu intercâmbio material com a natureza. Defronta-se com a natureza como uma de suas forças" (MARX, 2013, p. 211), apropriando-se de seus recursos naturais, com intuito de dar-lhes alguma finalidade em seu auxílio existencial, transformando o meio natural de acordo com suas necessidades impostas. Dessa forma, agindo "sobre a natureza externa e modificando-a, ao mesmo tempo que modifica a sua própria natureza. Desenvolve potencialidades nela adormecidas e submete ao seu domínio o jogo das forças naturais" (MARX, 2013, p. 211).

Para Marx, não se trata de uma relação imediata, ou melhor, de "formas ainda instintivas de trabalho [pressupõe-no] sob a forma exclusivamente humana" (MARX, 2013, p. 211); mas de uma capacidade de "ideação prévia" que pertence especificamente ao homem.

Uma aranha executa operações semelhantes às do tecelão, e a abelha supera mais de um arquiteto ao construir sua colméia. Mas o que distingue o pior arquiteto da melhor abelha é que ele figura na mente uma construção antes de transformá-la em realidade. No fim do processo do trabalho aparece um resultado que já existia antes idealmente na imaginação do trabalhador. Ele não transforma apenas o material sobre o qual opera; ele imprime ao material o projeto que tinha conscientemente em mira, o qual constitui a lei determinante do seu modo de operar e ao qual tem de subordinar sua vontade. E essa subordinação não é um ato fortuito (MARX, 2013, p. 210-211). 
Esta passagem d'O Capital, utilizada de forma exaustiva por diversos autores, explicase o seu uso pelo contexto rico em significações, como um dos trechos mais completos acerca da explicação dos sentidos do trabalho enquanto ponto de centralidade na constituição do ser, como uma atividade exclusivamente humana em seu momento de virada ontológica (LUKÁCS, 2013), surgindo como uma abstração concreta do homem, que parte da realidade existente, não de forma instintiva, mas também por meio de uma idealização transformadora desta.

Nesse processo, o trabalho é considerado atividade ordenada por uma finalidade, o objeto do trabalho como a matéria transformada e os meios instrumentais de realização desta atividade (MARX, 2013). Para Marx (2013), todo trabalho tem uma finalidade em sua atividade, sendo os recursos da natureza, devido sua existência independente do homem, "o objeto universal do trabalho humano", onde "todas as coisas que o trabalho apenas separa de sua conexão imediata com seu meio natural que constituem os objetos de trabalho, fornecidos pela natureza". Estes recursos extraídos da natureza (matéria-prima) pelo trabalho é objeto do mesmo. Porém, nem "todo objeto de trabalho é matéria-prima" (MARX, 2013, p. 212) e para considerar-se como tal, exige-se sua modificação pelo trabalho. Em relação aos instrumentais de trabalho na transformação desta matéria, Marx afirma que é uma "coisa ou um complexo de coisas que o trabalhador insere entre si mesmo e objeto trabalhado [que] lhe serve para dirigir sua atividade sobre o objeto" (MARX, 2013, p. 213). Os meios de trabalho atuam sobre o meio natural "de acordo com o fim que mira” (MARX, 2013, p. 213).

E à medida que se desenvolvem os processos são exigidos meios de trabalhos mais elaborados, e a cada momento de complexificações objetivas, impõem-se necessariamente subjetividades, não no sentindo instintivo-imediato, mas de forma elaboradamente pensada, em que o resultado pode ou não ser o esperado. Por exemplo, "nas cavernas mais antigas habitadas pelos homens, encontramos instrumentos e armas de pedra" (Marx, 2013, p. 213), criadas/construídas mediante as exigências desafiantes da existência.

Desse modo, nota-se que o trabalho desde suas manifestações mais primitivas surge de forma decisiva na organização dos seres humanos, transformando e sendo transformado no transcorrer do tempo e sob as condições exigentes do espaço, com as objetivações do tipo de sociedade vigente, inseridas na totalidade da esfera do vivido. Assim, o trabalho coloca-se enquanto complexo gerador de outros complexos sociais, entre os quais a Educação. Incidindo sobre costumes, leis, valores, formas de lazer, cultura etc., enfim, em todos os 
complexos exclusivamente pertencentes ao ser social. Por isso, indica-se o trabalho como condição de inseparabilidade com a produção da existência, como complexo essencial no desafiar ininterrupto e contraditório nas relações entre os indivíduos enquanto sujeitos históricos, assumindo uma função paidética-educativa/formativa, colocado, assim, como "princípio educativo"3.

Para Engels (1979, p. 215), “o trabalho é condição fundamental de toda a vida humana; e o é num grau tão elevado que num certo sentido, pode-se dizer: O trabalho, por si mesmo, criou o homem". O trabalho é colocado como mediação entre sujeito e objeto, no qual a objetivação objetiva a subjetivação, considerando essa relação por meio de uma atividade instrumentalmente realizada por um sujeito que produz, trabalha, exige uma finalidade no ato transformador, inconsciente ou conscientemente planejada pelo sujeito que trabalha. No qual, criam-se instrumentos de mediação desta realidade, impondo ao homem a questão da necessidade de um fim aos meios escolhidos, em que se busca uma utilidade a esta forma de mediação.

O processo de trabalho surge, dessa forma, como gerador de valores de uso enquanto forma de apropriação do meio natural para suprir as necessidades, situando-se como mediação indissolúvel entre o homem e a natureza, "é condição eterna da vida humana, sem depender, portanto, de qualquer forma dessa vida, sendo antes comum a todas as suas formas sociais" (MARX, 2013, p. 218).

Essa relação metabólica entre o homem e a natureza, tendo o trabalho como mediação e criador de valores de uso, inerente a atividade humana na produção material da existência, não-alienada, constructor do ser social, é condição fundamentalmente imprescindível da existência humana, em uma relação de dependência e independência com o meio natural, em que ser humano pelo trabalho cria o ponto novo de existência, definindo-o num estágio superiormente mais evoluído.

Para Lukács (2013), o trabalho deve ser entendido como categoria primordial em relação às demais categorias específicas na constituição do ser social em uma concepção ontológica objetiva, como ponto fundante, compreendido enquanto totalidade, na qual é essencial, ao iniciar a explicação acerca deste ser, preservar o sentido relevante das complexificações constitutivas do ser social, concebendo suas "categorias decisivas, como o trabalho, a linguagem, a cooperação e a divisão do trabalho" numa totalidade, pois "nenhuma dessas categorias pode ser adequadamente compreendida se for considerada isoladamente" 
(LUKÁCS, 2013, p. 41). Mais adiante, o autor assevera sua posição metodológica, afirmando que, devido a essa dificuldade e com intuito de desenriçar o ponto de crítica sobre a totalidade parcialmente conhecida de forma imediata,

[...] devemos recorrer ao método marxiano das duas vias, [...] primeiro decompor, pela via analítico-abstrativa, o novo complexo do ser, para poder, então, a partir desse fundamento, retornar (ou avançar rumo) ao complexo do ser social, não somente enquanto dado e, portanto, simplesmente representado, mas agora também compreendido na sua totalidade real (LUKÁCS, 2013, p. 42).

Para Raniere (2011), Lukács na Ontologia do Ser Social aponta questões que reforçam alguns acertos do idealismo em reflexões sobre o trabalho, "ao confrontar elementos da causalidade com aqueles da teleologia", entendendo o trabalho como mediação "da relação estabelecida entre homem e natureza" (RANIERE, 2011, p.116). Por outro lado,

[...] o materialismo mostra também o quanto o idealismo errou ao não compreender que a teleologia (a posição conforme os fins) não existe em outra esfera a não ser aquelas do trabalho humano - não existe, sob este ponto de vista, nenhum criador universal, nenhuma inteligência superior à do próprio homem (RANIERE, 2011, p. 116).

A esse respeito, Marx afirma na tese $8^{\circ}$ sobre Feuerbach que "a vida social é essencialmente prática. Todos os mistérios, que levam a teoria ao misticismo, encontram sua solução racional na práxis humana e no ato de compreender essa práxis” (2007, p. 613). Tendo em vista que, "as alternativas são sempre concretas" inseparáveis de seu "aqui e agora (hic e nunc)", sob uma concretude articulatória entre o "homem singular e as circunstâncias sociais" (SANTOS NETO, 2013, p. 66-67), encontrando no trabalho o complexo fundante dos demais complexos sociais, como condição afirmadora do homem enquanto ser social, possibilitada por um "salto ontológico" (LUKÁCS, 2013).

O salto ontológico referido por Lukács (2013), constitui-se em uma ruptura com a normalidade do desenvolvimento, implicando uma mudança qualitativa e estrutural do ser, em que no momento inicial, certamente, é possuidor de premissas e possibilidades dos instantes posteriores e "superiores" (RANIERE, 2011). Contudo, discorrer sobre o ser social como sujeito do trabalho, trata-se de um movimentar-se histórico-dialético, e por esse caráter nãonaturalizado impossibilita-se o retorno a mesma posição. Há, portanto, um movimento em 
espiral, onde em cada ascenso-retorno-ao-não-mesmo surgem novas complexificações exigentes de serem apreendidas, e esse caráter de irreversibilidade-histórica é o que "impede de reconstruir por meio de experiências, o hic et nunc [aqui e agora] social desse estágio de transição" (LUKÁCS, 2013, p. 42). Por esse motivo,

[...] o máximo que se pode alcançar é um conhecimento post festum, aplicando o método marxiano, segundo o qual a anatomia do homem fornece a chave para anatomia do macaco e para o qual um estágio mais primitivo pode ser reconstruído intelectualmente - a partir do estágio superior, de sua direção de desenvolvimento, das tendências de seu desenvolvimento (LUKÁCS, 2013, p. 42-43).

Compreendendo, dessa forma, a essência do trabalho humano em uma luta contínua pela existência fincada em uma autoatividade (MARX, 2010), que necessariamente ocorre por meio de um "salto ontológico" em transição qualitativamente diferente de um estágio de ser a outro superior, do em si ao para si (LUKÁCS, 2013), afastando-se de um impedimento natural (MARX, 2007), desafiando as condições de sua existência-subsistencial reprodutiva e, para-além disso, construindo/reconstruindo o mundo, transformando-o por meio de sua práxis não mais condicionada aos aspectos naturais, mas num campo histórico, em que a "essência do trabalho humano consiste no fato de que em primeiro lugar, ele nasce em meio a luta pela existência e, em segundo lugar todos seus estágios são produto de sua 'autoatividade"” (LUKÁCS, 2013, p. 43).

De acordo com Raniere (2011, p. 117-118):

A característica do nascimento do trabalho é, portanto, antes qualitativa do que propriamente quantitativa, uma vez que a partir do trabalho tem-se a origem de novas objetividades. Assim, a posição teleológica se torna o modelo do conjunto da práxis social e, por este meio, toda e qualquer posição é no limite, uma posição material - o trabalho é no que diz respeito à formação do ser, sempre a forma originária.

Essa posição de primazia do trabalho fundada no "processo e gênese do ser social" na concepção "ôntica concreta" justifica-se na visão de que "no trabalho estão contidas in nuce todas as determinações constituintes da essência do novo ser social” (LUKÀCS, 2013, p. 44).

Lukács afirma (2013, p. 44) que: 
[...] todas as outras categorias dessa forma de ser, tem já em essência, um caráter puramente social, suas propriedades seus modos de operar somente se desdobram no ser social já constituído; quaisquer manifestações delas, ainda que sejam muito primitivas, pressupõem o salto como já acontecido. Somente o trabalho tem, como sua essência ontológica, um claro caráter de transição: ele é, essencialmente, uma inter-relação entre homem (sociedade) e natureza, tanto inorgânica (ferramenta, matéria-prima, objeto de trabalho etc.) como orgânica, inter-relação que pode figurar pontos determinados da cadeia (...) mas antes de tudo assinala a transição do homem que trabalha, do ser meramente biológico ao ser social.

Dessa forma, o homem irrompe com o caráter determinista da natureza, sendo tal condição decisiva ao "salto ontológico", na transição do homem que trabalha, de meramente biológico ao ser social. Tendo, assim, o trabalho como categoria fundante do ser social, proveniente de um princípio natural, rompido com o "curso normal do desenvolvimento", pressupondo uma transformação "qualitativamente estrutural do ser", em que no instante inicial, detém proposições e possibilidades de estágios mais elevados, mas não como uma "retilínea continuidade. A essência do salto é constituída por essa ruptura com a continuidade normal do desenvolvimento e não pelo nascimento, de forma súbita ou gradativa, no tempo, da forma de ser" (LUKÁCS, 2013, p. 46-47) ${ }^{4}$.

Lukács (2013), aponta em Engels (1979), na Dialética da Natureza, como o responsável por essa centralidade do trabalho no processo de "humanização do homem", investigando o caráter biológico do "novo papel que o trabalho adquire com o salto do animal ao homem" (LUKÁCS, 2013, p. 45).

Nas palavras do próprio Engels (1979, p. 216, grifo nosso)

[...] não houve, até hoje, mão de macaco por mais hábil, que tivesse feito a mais simples faca de pedra. As manipulações a que nossos antepassados aprenderam a adaptar gradualmente suas mãos (durante a transição do macaco ao homem), no transcurso de muitos milênios, só podiam ter sido, portanto, muito simples, a princípio. Os mais primitivos dos selvagens, mesmo aqueles nos quais se possa admitir um retrocesso ao estado mais rudimentar, apresentando uma regressão paralela em suas formas corporais, se encontram muito acima desses seres de transição. Até que o primeiro fragmento de sílica fosse transformado numa faca, pela mão humana, podem ter transcorrido intervalos de tempo ao lado dos quais o tempo histórico conhecido é uma coisa insignificante. Mas o passo decisivo fora dado: a mão humana tinha sido libertada e poderia, sem cessar, ir adquirindo novas habilidades, sendo que a maior delas, assim conseguida, podia ser herdada e melhorada, de geração em geração. 
Um "salto", na visão de Lukács, qualitativamente ontológico, para-além da esfera do orgânico, uma forma ulterior e não-natural que diz respeito unicamente ao homem. Portanto, "não se trata aqui das formas instintivas, animais, de trabalho. [Pressupõe-se] o trabalho sob a forma exclusivamente humana" (MARX, 2013, p. 211). Sendo a capacidade de ideação prévia (LUKÁCS, 2013) acerca da transformação da natureza do homem uma das questões decisivas na distinção em relação aos demais animais, pois,

[...] no fim do processo de trabalho aparece um resultado que já existia antes idealmente na imaginação do trabalhador. Ele não transforma apenas o material sobre o qual opera; ele imprime ao material o projeto que tinha conscientemente em mira, o qual constitui a lei determinante do seu modo de operar e ao qual tem de subordinar sua vontade. E essa subordinação não é um ato fortuito. Além do esforço dos órgãos que trabalham, é mister a vontade adequada que se manifesta através da atenção durante todo o curso do trabalho (MARX, 2013, p. 211-212).

A “ideação prévia” somente ocorre quando há uma objetivação do sujeito no mundo natural, transformando-o de acordo com as necessidades exigidas pelo sujeito em seu tempo e espaço histórico presente. Logo, pressupõe-se uma indissolubilidade entre subjetivação e objetivação do sujeito na realização do trabalho no momento de transformação da natureza e criação de novas necessidades apartadas de uma condição natural que é geneticamente determinada. Destarte, o "trabalho se torna o modelo de toda a práxis social, na qual, com efeito - mesmo que através de mediações às vezes muito complexas -, sempre se realizam pores teleológicos ${ }^{5}$, em última análise, de ordem material” (LUKÁCS, 2013, p. 47).

Marx (2013, 2010, 2007) opõe-se a uma concepção teleológica fora da práxis humana, e para ele "o trabalho não é uma das formas fenomênicas da teleologia em geral, mas o único ponto onde se pode demonstrar ontologicamente um pôr teleológico, como momento real da realidade material" (LUKÁCS, 2013, p. 51). Entretanto, Lukács adverte que tal condição de rigorosidade teleológica em Marx não possui caráter reducionista ou excludente de outras formas do ser,

[...] pelo contrário, ele aumenta, já que é preciso entender que o mais alto grau do ser que conhecemos, o social, se constitui como grau específico, se eleva a partir do grau em que está baseada a sua existência, o da vida orgânica, e se torna um novo tipo autônomo de ser, somente porque há nele esse operar real do ato teleológico. Só podemos falar racionalmente do ser social quando concebemos que sua gênese, o seu distinguir-se da sua própria base, seu tornar-se autônomo baseiam-se no 
trabalho, isto é, na contínua realização de pores teleológicos (LUKÁCS, 2013, p. 52).

Logo, não se trata de um conhecer condicionado por uma "ideação prévia", mas a uma atividade que pressupõe um sujeito objetivando-a, na qual são reproduzidas representações acerca da realidade, de onde se abstraem novas circunstâncias visando uma totalidade, por meio de um comunicar-se oriundo do trabalho, em que a linguagem também tem sua devida importância na apreensão e transformação do meio natural, considerando que, por intermédio desta, o homem constrói suas representações sobre o mundo circundante.

Entretanto, esta importância condiciona-se enquanto compreendida em um processo de trabalho constituído em necessária articulação comunicativa no ato do trabalho, como forma de manifestação não-natural, entre sujeitos com finalidade comum na sociabilidade, onde o metabolismo presente entre homens e natureza incide nas relações sociais da sociedade. "Atuando assim sobre a natureza externa e modificando-a, ao mesmo tempo [em que] modifica sua própria natureza”, agindo como sujeitos históricos responsáveis pela construção de si e do outro, que interagem por meio do trabalho e outras formas secundárias com a natureza e seus pares, como questão de sobrevivência ante as objetivações, pois nenhuma sociedade existe sem modificar o meio natural, sendo o ponto de transformação condicionado às objetivações do tempo-espaço histórico vigente. Entretanto, a única constante encontra-se nessa necessidade reprodutiva dependente da transformação da natureza.

Nisso, nota-se a importância de compreender o papel do trabalho na "reprodução da vida humana", considerando que este "representa para além dessa reprodução, o caráter abstrato (ou seja, conceitual) de incorporação de necessidades que aparecem para nós como elementos constituintes de nossa existência”, em novas formas além-produtos, em que o trabalho origina algo novo, "vinculado à categoria da gênese social" (RANIERE, 2011, p. 119), como fundante na construção dos meios para suprir as necessidades.

O trabalho como categoria de centralidade na relação entre o homem e natureza que fundamentalmente é o meio de satisfação das necessidades e também criador de novas, tem sua dinâmica num "movimento de unidade entre sujeito e objeto" (RANIERE, 2011, p.126), em que o sujeito do trabalho interage diretamente na natureza, como "mediação da consciência", na qual tem na produção a realização e incorporação social da necessidade 
tornada consciente, sendo preponderante nessa questão a forma assumida pela consciência colocada como fenômeno central na sua consecução. Visto que,

[...] toda atividade humana está determinada por certo gradiente de intencionalidade - a consciência é responsável tanto pela reprodução conceitual (a abstração que coloca no centro da atividade, ao mesmo tempo, a conexão entre meios e fins e também a ideação prévia a respeito do objeto) como pela produção espiritual, esta resultante da atividade mais complexa do ser humano, na esfera da criação já distanciada da relação imediata entre homem e natureza, mas cuja complexificação só tornou-se possível, graças à sociablização primeira do elemento natural (RANIERE, 2011, p. 130).

Logo, não há um movimento autônomo entre ideias e representações construídas pela consciência, e sim a existência de um "movimento de unidade entre sujeito e objeto", no qual existe uma necessária "conexão entre meios e fins, a ideação prévia" do objeto e as novas formas complexificadas assumidas por meio da "socialização primeira do elemento natural". Nas palavras de Marx \& Engels,

\begin{abstract}
Os homens são os produtores de suas representações, de suas idéias e assim por diante, mas os homens reais, ativos, tal como são condicionados por um determinado desenvolvimento de suas forças produtivas e pelo intercâmbio que a ele corresponde, até chegar às suas formações mais desenvolvidas. A consciência [Bewusstein] não pode jamais ser outra coisa do que ser o consciente [Bewusstw Sein], e o ser dos homens é o seu processo de vida real (MARX \& ENGELS, 2007, p.48).
\end{abstract}

Por conseguinte, pensar em superação das condições de estranhamento da sociedade exige tal compreensão "a partir do autodesenvolvimento ontológico do trabalho", que em Marx surge como questão decisiva para a humanidade, considerando que sem a apropriação pelo homem das forças exteriores a ele e sem o "entendimento dos elementos causais internos à realização dessas forças" (RANIERE, 2013, p.130) a lógica da existência humana seria impossível. De acordo com Adolfo Vázquez (2013), é pelo trabalho como produção da vida material e espiritual o momento do para-além do homem, em que se eleva sobre "a natureza exterior e sua própria natureza, e é nessa superação de seu ser natural que consiste propriamente sua autoprodução" (p. 130). Essa é a forma do trabalho ontológico, enquanto condição plena do ser, partícipe da dialética entre homem e natureza. 


\section{CONSIDERAÇÕES FINAIS}

A originalidade da abordagem ontológica marxiana está em estabelecer uma descrição ontológica do ser social sobre bases materialistas (LUKÀCS, 2013), na medida em que situa o trabalho como ponto de centralidade da práxis humana, onde tenta apreender a sua constituição interna. A dinâmica dessa relação de "produção e reprodução [...] denomina-se essência, e as formas particulares desta em tempo e espaço específicos, como formas de aparecer, de fenômenos" (RANIERE, 2011, p. 131), considerando o trabalho em articulação com os demais complexos, como categoria central do ser social, onde a "essência do ser social é, portanto, todo o processo passado do qual ela mesma é o resultado" (RANIERE, 2011, p. 134).

Portanto, o trabalho é a mediação fundamental na relação entre homem e natureza, pois só através dele o homem sobrevive (LUKÀCS, 2013). E quando se considera tal premissa, afirma-se, assim, a importância desta práxis enquanto ontologicamente fundamental, associando-o de forma indissolúvel a produção da vida material da existência, que metabolicamente reproduz o ser social (MARX, 2013), pois “o trabalho constitui-se como categoria intermediária que possibilita o salto ontológico das formas pré-humanas para o ser social. Ele está no centro do processo de humanização do homem" (ANTUNES, 2009, p. 139).

Trata-se, então, do trabalho como ponto de centralidade e fundante do ser social, criador de valores de uso, como mediação entre homem e natureza, da qual "deriva todo o processo de formação humana. A produção aparece como a forma de o homem se manter, além de configurar a forma de ele definir e orientar suas necessidades" (RANIERE, 2010, p. 14), que são repostas e renovadas pela produção, tendo como marco-chave a relação entre o ser humano e o meio natural. Tal forma assume-se "ontologicamente objetiva", como uma atividade inerente, inseparável, indissolúvel da necessidade de preservação da espécie humana, em que isso exige um educar do trabalho como forma de efetivação do homem.

\section{REFERÊNCIAS}

ANTUNES, Ricardo. Os sentidos do trabalho: ensaio sobre a afirmação e negação do trabalho. 2. ed. São Paulo: Boitempo, 2009. 
ENGELS, Friedrich. A dialética da natureza. 3. ed. Rio de Janeiro: Paz e Terra, 1979.

GRAMSCI, Antonio. Cadernos do cárcere. Vol. 2. 7. ed. Trad. Carlos Nelson Coutinho. Rio de Janeiro: Civilização Brasileira, 2014.

Americanismo e Fordismo. Trad. Gabriel Bogossian. São Paulo: Hedra, 2008.

Os intelectuais e a organização da cultura. 8. ed. Trad. Carlos Nelson Coutinho. Rio de Janeiro: Civilização Brasileira, 1991.

KOSIK, Karel. Dialética do concreto. Trad. Celia Neves e Alderico Toríbio. $2^{\text {a }}$. ed. Rio de Janeiro: Paz e Terra, 1976.

HEGEL, Georg Wilhelm Friedrich. Ciência da Lógica. Trad. Marco Aurélio Werle. São Paulo: Bacarolla, 2011.

LUKÁCS, György. Para uma ontologia do ser social II. Trad. Nélio Schneider, Ivo Tonet e Ronaldo Vielmi Fortes. São Paulo: Boitempo, 2013.

Prolegômenos para uma ontologia do ser social. Trad. Lya Luft e Rodnei Nascimento. São Paulo: Boitempo, 2010.

MARX, Karl. O capital. Crítica da economia política: livro I. Vol. 1. O processo de produção do capital. Trad. Reginaldo Sant'Anna. 31. ed. Rio Janeiro: Civilização Brasileira, 2013.

. Manuscritos econômico-filosóficos. Trad. Jesus Raniere. São Paulo: Boitempo, 2010.

A ideologia Alemã. Trad. Marcelo Backes. Rio de Janeiro: Civilização Brasileira, 2007. 
PISTRAK, Moisey Mikhaylovivh Ensaios sobre a escola politécnica. Trad. Alexey Lararev e Luiz Carlos Freitas. São Paulo: Expressão Popular, 2015.

Fundamentos da escola do trabalho. 3. ed. Trad. Daniel Aarão Reis Filho. Rio de Janeiro: Expressão Popular, 2011.

PISTRAK, Moisey Mikhaylovich (org.). A escola-comuna. 2. ed. Trad. Luiz Carlos Freitas e Alexandra Marenich. São Paulo: Expressão Popular 2013.

RANIERE, Jesus. Apresentação. In: MARX, Karl. Manuscritos econômico-filosóficos. Trad. Jesus Raniere. São Paulo: Boitempo, 2010.

Trabalho e dialética. Hegel, Marx e a teoria social do devir. São Paulo: Boitempo, 2011.

SANTOS NETO, Artur Bispo dos. Trabalho e Tempo de Trabalho na perspectiva marxiana. São Paulo: Instituto Lukács, 2013.

SAVIANI, Demerval. Pedagogia histórico-crítica. Campinas: Autores Associados, 2012. Trabalho e educação: fundamentos ontológicos e históricos. Revista Brasileira de Educação. v.12. n.34. jan./abr., 2007.

\footnotetext{
${ }^{1}$ Mestre em Educação (PPGE - UFMA). Graduado em Filosofia (UECE). Professor de Filosofia/ Filosofia da Educação do Instituto Federal de Educação, Ciência e Tecnologia do Maranhão - Campus Pinheiro (IFMA). email: vicentesobreirajr@live.com.

${ }^{2}$ Doutora em Educação (UFC/FACED). Mestre em Educação (UFMA). Especialista em Metodologia do Ensino Superior (UFMA). Professora do Programa de Pós-Graduação em Educação (PPGE) stricto sensu da Universidade Federal do Maranhão (UFMA). e-mail: isoamri@bol.com.br

${ }^{3}$ A esse respeito ver Gramsci $(2014,2008,1991)$ e Pistrak $(2015,2013,2011)$. Gramsci no intento construtor de um processo de formação da cultura como instrumento de luta na Itália fascista e Pistrak no curso pós-revolução comunista, em 1917, na União Soviética, como tentativa de construção de uma pedagogia comunista capaz de edificar a sociedade pós-revolucionária. Ver também Saviani (2012) ao propor uma pedagogia marxista indicando alguns conceitos importantes aos estudos em educação, tais como o do "trabalho como princípio educativo" por exemplo. Com o conceito do "trabalho como princípio educativo", tenta-se resgatar a dimensão histórico-ontológica do trabalho enquanto essência fundamental na constituição da sociabilidade humana, demonstrando sua essenciabilidade na produção das condições materiais da existência humana, para a qual, necessariamente precisa-se adquirir certo aprendizagem. Entretanto, nessa perspectiva efetivadora, o saber não é 
construído separadamente, como algo exterior, mas, de maneira indissolúvel. Assim, Saviani (2012) tenta demonstrar historicamente que a relação entre trabalho-educação detém uma identidade, perdida na sociedade capitalista. Para o autor em um de seus trabalhos: $\mathrm{O}$ ponto de partida à relação entre trabalho-educação é entendê-la como uma relação de identidade. "Os homens aprendiam a sua existência no próprio ato de produzila. Eles aprendiam a trabalhar trabalhando. Lidando com a natureza, relacionando-se uns com os outros, os homens educavam-se e educavam as novas gerações. A produção da existência implica o desenvolvimento de formas e conteúdos cuja validade é estabelecida pela experiência, o que configura um verdadeiro processo de aprendizagem. Assim, enquanto os elementos não validados pela experiência necessitam ser preservados e transmitidos às novas gerações no interesse da comunidade da espécie”. (SAVIANI, 2007, p. 155)

${ }^{4}$ Ressalta-se que qualidade e quantidade não são apresentadas por Lukács como formas divergentes ou isoladas no ser. É opostamente a essa forma gnosiológica de exterioridade objetal abstrata, que o autor desenvolve sua ontologia, onde quantidade e qualidade são postas também como "categorias de complexos processuais, como forma e conteúdo, como parte e o todo etc.[...]", em quais "[...] as determinações mais gerais do ser se deixam apresentar como momentos dessas totalidades dos complexos processuais". Visto que, enquanto determinações, atuam sempre como relações indissolúveis e recíprocas das "determinações mais gerais dos complexos processuais, que sem tais inter-relações inseparáveis dos pares categoriais jamais teriam podido adquirir determinações concretas de objetividade" (LUKÁCS, 2010, p. 186). Importante pontuar que Lukács (2010) vem construindo argumentações em defesa da ontologia do ser social, e na questão acerca da relação entre qualidade e quantidade, parte da concepção hegeliana presente na Ciência da Lógica (2011), apontado inclusive acertos em Hegel.

${ }^{5}$ “O fato simples de que no trabalho se realiza um pôr teleológico é uma experiência elementar da vida cotidiana de todos os homens, tornando-se isso um componente imprescindível de qualquer pensamento, desde os discursos cotidianos até economia e a filosofia. O problema que aqui surge não é tomar partido a favor do caráter teleológico do trabalho ou contra, antes, o verdadeiro problema consiste em submeter a um exame ontológico autenticamente crítico a generalização ilimitada - e novamente: desde a cotidianidade até o mito, a religião e a filosofia - desse fato elementar" (LUKÁCS, 2013, p. 47)

RECEBIDO EM: Setembro de 2016

APROVADO EM: Dezembro de 2016 